\title{
Health Claims: Let Science Prevail
}

\author{
Berthold Koletzko \\ Division of Metabolic and Nutritional Medicine, Dr. von Hauner Children's Hospital, University of Munich \\ Medical Centre, Munich, Germany
}

On March 16, 2011, a slight majority of members of the European Parliament's Committee on Environment, Public Health and Food Safety adopted a resolution aiming at the refusal of authorising a health claim on infant foods (30 votes in favour, 28 against, 1 abstention) [1]. This resolution opposes the adoption of the health claim 'Docosahexaenoic acid (DHA) intake contributes to the normal visual development of infants up to 12 months of age', which had been recommended for adoption by both the European Commission and the Standing Committee on Food of the European Member States. Following this committee vote, the European Parliament's plenary will now have to take a decision in the near future as to whether it supports or rejects the adoption of this health claim.

How did this amazing controversy evolve? The European regulation on health claims for foods stipulates that these should be truthful and based on generally accepted scientific evidence of the relationship between diet and health [2]. Scientific substantiation should be the main aspect to be taken into account for the use of nutrition and health claims, and it should be based on the totality of available scientific data [2]. The European Food Safety Authority (EFSA) has been charged to perform this scientific evaluation, with the help of qualified scientists. In the current case, EFSA has reviewed the available evidence. It concluded that a cause and effect relationship is established between the intake of infant and follow-on formulae supplemented with docosahexaenoic acid (DHA) at levels at or above $0.3 \%$ of total fatty acids and visual function at 12 months in formula-fed infants, and also in breastfed infants receiving such formulae after weaning [3]. EFSA concluded that the wording 'DHA contributes to the visual development of infants' reflects the scientific evidence but should be restricted to formulae that contain at least $0.3 \%$ of the total fatty acids as DHA.

While this seemed like a straightforward case based on adequate scientific data, an activist group in the United Kingdom embarked on active lobbying against the adoption of this health claim, apparently driven by the conviction that no infant food should bear health claims. The activist group convinced some members of the $\mathrm{Eu}-$ ropean Parliament to support its cause and to propose the cited resolution, which has adopted a number of pseudoscientific arguments of the activists, unfortunately without critical evaluation of their validity.

The adopted resolution reports that scientific evidence shows a benefit of DHA in breast milk for the visual development of infants, whereas such effects of DHA in formula had not been demonstrated. To support this conclusion, one single systematic review is cited which states that there would be no conclusive evidence for benefits of adding the $\omega-3$ fatty acid DHA to infant formulae, although the authors acknowledged that some studies found benefits on visual function [4]. However, in contrast to the EFSA analysis, these authors did not consider the amount of DHA added to formula as a predictor of outcome.

\section{KARGER}

Fax +4161306 1234

E-Mail karger@karger.ch

www.karger.com
(C) 2011 S. Karger AG, Basel

0250-6807/11/0581-0079 \$38.00/0

Accessible online at:

www.karger.com/anm
Prof. Berthold Koletzko, MD

Division of Metabolic and Nutritional Medicine

Dr. von Hauner Children's Hospital, Ludwig-Maximilian University of Munich

Lindwurmstrasse 4, DE-80337 Munich (Germany)

Tel. +49895160 2826, E-Mail office.koletzko@med.uni-muenchen.de 
EFSA based its conclusions on this question not on a single, selected publication, but reviewed the totality of available data with the required scientific accuracy. EFSA evaluated 43 relevant scientific publications, including 13 publications on randomised clinical trials [3]. The evaluation performed by EFSA is thorough and meets high scientific standards. It is very surprising and disturbing that the members of the European Parliament find such a profound scientific evaluation by an independent body less convincing than the arguments of a loud-mouthed lobbying group.

The resolution also raises concerns on the safety of adding the $\omega-3$ fatty acid DHA to infant formulae, borrowing analogous statements of the said activist group. This is anomalous since independent from any potential health claims, any formula for infants is only suitable for marketing in Europe if it is safe for infant feeding [5]. European legislation supported by the European Parliament accepted the optional addition of DHA and other long-chain polyunsaturated fatty acids to infant and follow-on formulae as a safe measure [5], based on a thorough scientific assessment of its suitability and safety by the Scientific Committee on Food [6].

The resolution raises worries on safety by referring to a follow-up study in a subgroup of 10-year-old children who had previously participated in an infant feeding study [7]. However, the citation of findings from this study is incomplete and misleading. An unbiased evaluation of this study leads to the conclusion that it does not at all demonstrate untoward effects of DHA addition to infant formulae. The authors revisited a small subgroup of $45 \%$ of the initial study population at the age of 10 years. The considerable attrition with a high potential for selection bias obviously limits the conclusions that can be drawn with respect to long-term effects of early feeding. Moreover, the study did not find any group differences for growth in the total study population, and among boys. The small group of 25 examined girls, who as infants had received an infant formula with DHA, was significantly taller at the age of 10 years (by about $4 \mathrm{~cm}$ ) than the group of girls who had received a control formula without DHA. The taller group of girls also had a proportionally higher body weight, whereas the body mass index was not different. As one would expect, also the mean blood pressure was slightly higher in the girls with a larger body size, which reflects the fundamental laws of physics: larger people have a higher blood pressure. Of importance, these evaluations represent a secondary subgroup data analysis deviating from the original study hypothesis. Therefore, these analyses do not have the power to demonstrate a causal relationship to the type of feeding provided in infancy. If one would wish to construct such a relation, one would actually have to conclude that DHA supply of infant formulae had a beneficial effect on length growth and not untoward effects.

Furthermore, the adopted resolution does not reveal that a systematic review and meta-analysis of a large number of controlled trials showed no effects of DHA enrichment of infant formulae on child growth [8]. Also, it does not refer to a follow-up study in children that had previously received infant formula with or without DHA [9]. Children in the DHA group did not differ in growth but showed a beneficial blood pressure-lowering effect at early school age. The rather selective presentation of data in the draft resolution is very disturbing since it does not facilitate a balanced and rational judgement by the members of parliament.

The resolution proposes that there would be no scientific agreement on the usefulness of providing the $\omega-3$ fatty acid DHA with food products for infants. This suggestion is in stark contrast to numerous national and international recommendations that uniformly recommend a DHA supply to infants and are supported i.e. by the World Health Organisation, the Food and Agriculture Organisation of the United Nations, the World Association of Perinatal Medicine, the Child Health Foundation, the Diabetic Pregnancy Study Group, the Early Nutrition Academy, the European Association of Perinatal Medicine, the European Society for Clinical Nutrition and Metabolism, the European Society for Paediatric Gastroenterology, Hepatology and Nutrition, the International Federation of Placenta Associations, the International Society for the Study of Fatty Acids and Lipids, and the French Food Safety Authority AFFSA.

Perhaps one might question whether there should be any health claims made for infant food products, since breastfeeding is clearly considered the optimal form of infant feeding which therefore must be strongly protected, promoted and supported [10]. However, not all infants are fully breastfed during the first half year of life and partially breastfed thereafter. For these infants, safe infant formulae of the highest possible quality are required, and health care professionals and families should be able to receive appropriate information on their characteristics [11]. European legislation supports that relevant science-based product properties can be declared for formulae for infants to allow for a selection of appropriate products by physicians, other health care professionals and families, given they are based on a properly scrutinised 
scientific basis (e.g. properties such as lactose free, hypoallergenic) [5]. In the European Union, EFSA has been charged with examining the scientific basis of potential further product claims, which EFSA performs with high scientific thoroughness applying very strict standards. Clearly, any decisions on the authorisation of health claims for food products for infants should be based on such a meticulous, medical-scientific evaluation and not on biased lobbying of activist groups.

Preventing communication of scientifically assured benefits of optimised products bears the risk that it may slow or even stop the significant quality improvements of foods for infants that has occurred over the last decades in numerous single steps, and which has led to large benefits for child health. In the future, manufacturers might not be willing any more to invest major resources into the development, clinical evaluation and implementation of further improvements, if there is no chance to communicate such improvements. Such a development may considerably compromise the further optimisation of infant nutrition which is so necessary for further improving child health. Therefore, it is truly important that science and not lobbying prevails in this matter.

\section{References}

1 Willmott G, Sarbu D, Childers N, Kadenbach K: Motion for a resolution pursuant to Rule 88(2) of the Rules of Procedure by Glenis Willmott, Daciana Sarbu, Nessa Childers and Karin Kadenbach on the draft commission regulation on the authorisation and refusal of authorisation of certain health claims made on foods and referring to children's development and health. European Parliament, Committee on the Environment, Public Health and Food Safety, Plenary Sitting 2011, B7 0000/2011.

2 EC Regulation No 1924/2006 of the European Parliament and of the Council of 20 December 2006 on nutrition and health claims made on foods. Official Journal of the European Union, 2007, L 12/3 (18.1.2007).

3 EFSA: Scientific opinion. DHA and ARA and visual development. Scientific substantiation of a health claim related to docosahexaenoic acid (DHA) and arachidonic acid (ARA) and visual development pursuant to Article 14 of EC Regulation No 1924/20061. Scientific opinion of the Panel on Dietetic Products, Nutrition and Allergies (question No EFSAQ-2008-211). Adopted on 22 January 2009. EFSA J 2009;941:1-14.
4 Simmer K, Patole SK, Rao SC: Longchain polyunsaturated fatty acid supplementation in infants born at term. Cochrane Database Syst Rev 2008:CD000376.

5 Commission Directive 2006/141/EC of 22 December 2006 on infant formulae and follow-on formulae and amending Directive 1999/21/EC. Official Journal of the European Union, 2006, L 401/1 (30.12.2006).

6 Scientific Committee on Food EC, Koletzko B, Saris W, Flynn A, Palou A, Wal JM, Hernell O, Jackson A, Przyrembel H, Turck D: Report of the Scientific Committee on Food on the revision of essential requirements of infant formulae and follow-on formulae. Brussels, European Commission, 2003.

7 Kennedy K, Ross S, Isaacs EB, Weaver LT, Singhal A, Lucas A, et al: The 10-year followup of a randomised trial of long-chain polyunsaturated fatty acid supplementation in preterm infants: effects on growth and blood pressure. Arch Dis Child 2010;95:588-595.
8 Makrides M, Gibson RA, Udell T, Ried K: Supplementation of infant formula with long-chain polyunsaturated fatty acids does not influence the growth of term infants. Am J Clin Nutr 2005;81:1094-1101.

-9 Forsyth JS, Willatts P, Agostoni C, Bissenden J, Casaer P, Boehm G: Long chain polyunsaturated fatty acid supplementation in infant formula and blood pressure in later childhood: follow up of a randomised controlled trial. BMJ 2003;326:953.

10 Agostoni C, Braegger C, Decsi T, Kolacek S, Koletzko B, Michaelsen KF, et al: Breastfeeding: a commentary by the ESPGHAN Committee on Nutrition. J Pediatr Gastroenterol Nutr 2009;49:112-125.

11 Koletzko B, Baker S, Cleghorn G, Neto UF, Gopalan S, Hernell O, et al: Global standard for the composition of infant formula: recommendations of an ESPGHAN coordinated international expert group. J Pediatr Gastroenterol Nutr 2005;41:584-599.

\section{European Parliament vote on Health Claim for Baby Foods}

Proposals to allow producers to claim that adding the fatty acid DHA to baby food 'contributes to the normal visual developments of infants up to 12 months of age' were backed by the European Parliament on April 6, 2011. The resolution opposing the plan did not achieve the majority of votes required (328 for, 323 against and 26 abstentions) and is therefore rejected.

http://www.europarl.europa.eu/en/pressroom/content/20110406IPR17110/html/ DHA-in-baby-food-European-Parliament-approves-health-claim 